\title{
SÉRGIO VAZ E A POESIA DAS “QUEBRADAS”: UM ESTUDO SEMIOLINGUÍSTICO ACERCA DAS COMPETÊNCIAS DE LEITURA
}

\author{
Janayna Rocha da Silva \\ Mestranda em Linguística - Estudos da Linguagem / Programa de Pós-graduação em \\ Estudos da Linguagem - Universidade Federal Fluminense (UFF) \\ rochajanayna1412@gmail.com \\ Joyce Silva dos Santos Monforte \\ Mestranda em Linguística - Estudos da Linguagem / Programa de Pós-graduação em \\ Estudos da Linguagem - Universidade Federal Fluminense (UFF) \\ joy-santos1@hotmail.com
}

\section{RESUMO}

Sérgio Vaz, ao produzir as suas poesias, constrói uma reflexão acerca da vida do jovem negro morador das periferias paulistanas. Assim, o seu texto busca provocar no leitor o "sentir". Muitas vezes, o sentimento de incômodo é o mais latente, já que, ao retratar as discrepâncias sociais presentes em nossa sociedade, o poeta parece buscar transportar o seu interlocutor a acionar os sentidos que abarquem o universo de injustiças, preconceitos e violência que envolvem distintas classes sociais. $O$ artigo busca, portanto, analisar quais competências precisam ser acionadas pelo leitor a fim de que a compreensão do texto literário seja realizada no maior número de camadas possível. Entendemos leitura competente a partir da perspectiva da Teoria Semiolinguística, postulada por Patrick Charaudeau. Dessa forma, o trabalho visa a identificar quais competências (CHARAUDEAU, 2001) precisam ser alcançadas pelo leitor para que os três níveis da linguagem (CHARAUDEAU, 2001) que constituem o texto sejam atingidos.

Palavras-chave: texto literário, semiolinguística, competências de leitura.

\section{RESUMEN}

Sérgio Vaz, al producir sus poesías, construye una reflexión acerca de la vida del joven negro morador de las periferias paulistanas. Así, su texto busca provocar en su lector el "sentir". Muchas veces, el sentimiento de incomodidad es el más latente, ya que, al retratar las discrepancias sociales presentes en nuestra sociedad, el poeta parece buscar transportar a su interlocutor a acionar los sentidos que abarquen el universo de injusticias, prejuicios y violencia que envuelven distintas clases sociales. El artículo busca, por lo tanto, analizar qué competencias necesitan ser accionadas por el lector a fin de que la comprensión del texto literario sea realizada en el mayor número de capas posible. Entendemos lectura competente desde la perspectiva de la Teoría Semiolingüística, postulada por Patrick Charaudeau. De esta forma, el trabajo busca identificar qué competências (CHARAUDEAU, 2001) necesitan ser alcanzadas por el lector para que los tres niveles del lenguaje (CHARAUDEAU, 2001) que constituyen el texto sean alcanzados.

Palabras-clave: el texto literario, la semiolinguística, las competencias de lectura. 


\section{Introdução}

A leitura é uma atividade humana importante, já que é por meio dela que o indivíduo aprende, ensina, sente, conhece novos lugares e novas histórias de vida. Contudo, para que ela seja fonte de prazer, deve-se "penetrar no sentido por meio da percepção mais aprofundada do jogo de palavras que constrói o texto" (REBELLO, 2016, p. 331). É necessário que o leitor consiga transpor a visibilidade das palavras para que assim alcance a invisibilidade que elas oferecem. Mas como um leitor poderia realizar tal feito? A partir dos pressupostos da Semiolinguística, Patrick Charaudeau (2001), ao abordar a produção e interpretação de textos orais e escritos, aponta que, no processo de interpretação, o alcance da invisibilidade dos ditos acontece quando o leitor torna-se "competente", sendo, portanto, capaz de relacionar os níveis que compõem o discurso textual para, de fato, interpretar os significados expressos pelo texto.

Tomando o ensino de Língua Portuguesa e Literatura como o espaço da formação de um leitor proficiente, assinalamos como importante e necessária a participação do professor de língua portuguesa no que tange à mediação de leitura com o fim de estimular os saberes dos discentes para a prática de leitura e interpretação textual e, assim, contribuir para a formação leitores competentes, capazes de extrapolar a superfície linguística e adentrar nos implícitos textuais. Assim, salientamos a importância da literatura nas aulas de língua portuguesa, já que, por meio da leitura de bons livros, o aluno assimila os mecanismos de funcionamento da língua ao mesmo tempo em que desenvolve a sua competência enquanto leitor. 
De acordo com a Semiolinguística, compreender e interpretar não são sinônimos. A compreensão está relacionada ao sentido de língua, sendo o primeiro sentido depreendido do texto, ou seja, é o momento no qual há a decodificação das palavras. Já a interpretação está relacionada ao sentido de discurso, sendo o segundo sentido produzido pelo texto, ou seja, é o momento no qual o leitor realiza inferências, pressuposições, analogias, identifica intertextualidades, a partir de seu conhecimento de mundo. O segundo sentido sempre irá sobrepor o primeiro, já que é por meio de sua assimilação que o leitor realiza uma leitura proficiente.

O corpus deste trabalho é constituído pela poesia “Os Miseráveis" (2013) de Sérgio Vaz. Desse modo, objetivamos verificar quais competências devem ser acionadas pelo leitor, a fim de que a leitura do texto ultrapasse o sentido de língua e alcance o sentido de discurso.

Portanto, a fim de alcançarmos os objetivos propostos, na próxima sessão, trataremos dos pressupostos teóricos que norteiam o trabalho. $\mathrm{Na}$ sequência, analisaremos o corpus e, posteriormente, discorreremos sobre as conclusões.

\section{A construção do sentido sob o viés da Semiolinguística}

A Semiolinguística considera o discurso como objeto de interação entre os sujeitos participantes do ato de comunicação, os quais fazem uso da linguagem com o intuito de falar sobre o mundo, recriando-o discursivamente.

Nesse sentido, dois processos constroem a significação global dos textos produzidos pelos participantes do ato de comunicação: a transformação e a transação que, unidos, 
compreendem a semiotização de mundo, ou seja, a totalidade significativa do discurso. A relação "forma-sentido", nessa perspectiva, retoma as relações entre significado e significante, postuladas por Saussure, que são vistas como a transformação do mundo em linguagem. Assim, tal relação equivale ao sentido de língua, explícito, denotado, dado pelo processo de transformação. A essa relação, em contrapartida, são acrescentados inúmeros implícitos advindos das circunstâncias materiais e situacionais que envolvem o discurso. Dessa maneira, a interação (re)significa a linguagem por meio da transação entre os sujeitos, conforme é exposto no diagrama de Charaudeau:

Figura 1 - Semiotização do mundo

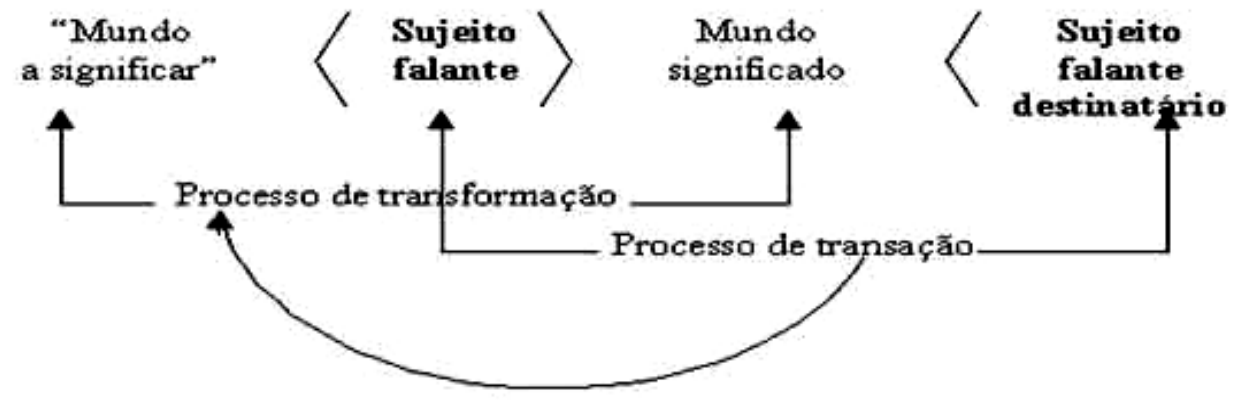

Fonte: Charaudeau (2005, p. 17)

Sendo construída por dois processos, a significação advém de uma série de explícitos e implícitos, apontando sempre um sentido comum, partilhado, porém ressignificado no discurso. Segundo Charaudeau, esse sentido comum equivale ao sentido de língua dado pelo processo de transformação. Nele o sistema linguístico é capaz de transformar "mundo a significar" em "mundo significado" a partir de categorias linguageiras que 
identificam os seres do mundo nomeando-os, que aplicam a esses seres propriedades, qualificando-os, que descrevem as ações nas quais esses seres estão engajados narrando, que fornecem os motivos dessas ações argumentando, que avaliam esses seres, essas propriedades, essas ações e esses motivos modalizando (CHARAUDEAU, 2007, p. 41).

Assim, esse processo engloba quatro tipos de operações necessárias à produção dos enunciados: a identificação, a qualificação, a ação e a causação, que definiremos como:

- Identificação: é o processo pelo qual nomeamos e conceituamos os seres do mundo, construindo, assim, a "identidade nominal”. Esse processo é realizado através da categoria dos substantivos.

- Qualificação: é o processo pelo qual caracterizamos, especificamos e discriminamos os seres do mundo, construindo, assim, a "identidade descritiva". Esse processo é realizado através da categoria dos adjetivos.

- Ação: é o processo pelo qual os seres do mundo agem ou sofrem a ação, construindo, assim, a "identidade narrativa". Esse processo é realizado através da categoria dos verbos.

- Causação: é o processo pelo qual a causa de certos acontecimentos é revelada, envolvendo os seres do mundo, construindo, assim, a "relação de causalidade". Esse processo é realizado através de modalizadores.

Essas operações são responsáveis pela manutenção de um significado comum, compartilhado pelos usuários de determinada língua e cultura, sentido que possibilita a presença de uma zona de intercompreensão comum entre as instâncias de produção e de recepção. Além do processo de transformação, há o processo de transação que engloba 
quatro princípios: o princípio de alteridade, o princípio de pertinência, o princípio de influência e o princípio de regulação. Vejamos cada um deles a seguir:

- Princípio de alteridade: segundo esse princípio, o ato de linguagem é um fenômeno que ocorre entre dois parceiros. Contudo, para que esse processo ocorra, é necessário que esses parceiros se reconheçam como semelhantes e também como diferentes. São semelhantes porque, para que haja uma troca entre eles, há a necessidade de que possuam saberes compartilhados e motivações comuns. São diferentes porque, para que o sujeito se reconheça como "Eu", é necessário que ele identifique as dissemelhanças com relação ao "Tu".

- Princípio de pertinência: de acordo com esse princípio, os atos de linguagem devem ser apropriados ao seu contexto e à sua finalidade, de modo que o sujeito comunicante possa atingir o parceiro durante a troca comunicativa.

- Princípio de influência: conforme esse princípio, o locutor possui a intenção de influenciar o seu interlocutor durante a troca comunicativa. Para que o objetivo seja atingido, aquele que comunica se utiliza de estratégias de persuasão e sensibilização, com o intuito de capturar o ouvinte.

- Princípio de regulação: esse princípio diz respeito ao que os participantes da troca comunicativa sabem a respeito do ato de linguagem de que participam. Dessa forma, há uma regulação do jogo de influências, para que a comunicação ocorra sem que haja nenhum confronto.

O processo de transação, portanto, delimita a significação do ato de linguagem através da interação entre os sujeitos, apreendendo a linguagem dentro de uma cadeia de fatores, dentre os quais colaboram para a significação a identidade dos sujeitos, os 
efeitos que pretendem produzir (e os que de fato são produzidos), o tipo de relação que pretendem instaurar e a forma como pretendem proceder para atingir seus objetivos, ou seja, todos os fatores determinados pela situação comunicativa, que definem o contrato e, logo, atribuem sentidos outros à língua. Tais fatores instauram sentidos possíveis nos discursos produzidos, já que "é o processo de transação que comanda o processo de transformação e não o inverso" (CHARAUDEAU, 2007, p. 41).

Dessa maneira, de acordo com a Semiolinguística, a produção e recepção dos sentidos não se dão de forma linear e transparente entre locutor e interlocutor, ao contrário, sua construção é opaca, já que o discurso não é significado apenas pela linguagem, mas, sobretudo, pelas circunstâncias em que ela é usada e por quem a usa. A comunicação, portanto, é concretizada através da relação intrínseca entre os dois processos, sendo necessário que as operações oriundas do processo de transformação sejam consideradas pelos sujeitos dentro de um quadro de ação, cujos fatores externos à linguagem influenciem a significação e estipulem um contrato comunicativo que reja todo 0 ato de linguagem.

De acordo com Charaudeau (2007), o contrato de comunicação é determinado pela situação de comunicação, que estipula um acordo prévio entre os sujeitos (locutor e interlocutor), segundo normas dadas por quadros de referências socialmente construídos e instituídos devido à memória dos sujeitos sobre outras práticas comunicativas. Assim, tais sujeitos agem discursivamente de acordo com regras socioinstitucionais dadas pela situação comunicativa na qual se veem engajados. O contrato, portanto, "resulta das características próprias à situação de troca, os dados externos, e das características discursivas decorrentes, os dados internos" (CHARAUDEAU, 2007, p. 68). 
Por serem definidos pela situação de comunicação, os dados discursivos do ato de linguagem preveem certos conhecimentos partilhados pelos sujeitos interagentes do ato de linguagem. É nessa perspectiva que os implícitos são adicionados aos ditos, visto que, ao produzir determinado discurso, o sujeito que comunica idealiza um interlocutor capaz de interpretar adequadamente o discurso considerando os sentidos dados pela situação de comunicação, como a identidade dos sujeitos e as relações existentes entre eles, as intenções que possuem, o tema de que tratam, sob que suporte e gênero estabelecem a troca, etc.

A noção de contrato pressupõe que a significação não é construída apenas no nível da linguagem, mas sim em três níveis: o situacional, o discursivo e o semiolinguístico, que, ao considerarem os dados externos e internos da comunicação, exigem dos sujeitos competências relacionadas a esses níveis para produzir significados, conforme postula Charaudeau:

La construcción del sentido, mediante cualquier acto de linguaje, procede de un sujeto que se dirige a outro sujeto, dentro de uma situación de intercambio específica, que sobredetermina parcialmente la elección de los recursos de lenguaje que pueda usar. Esto me ha llevado a elaborar un modelo que consta de tres niveles, con tres tipos de competencia correspondientes para el sujeto: nivel situacional y competencia situacional, nivel discursivo y competencia discursiva, nivel "semiolinguistico" y competencia "semiolinguística"ii (CHARAUDEAU, 2001, p. 4).

Sendo determinado por um contrato, que define o modo de tomada da palavra em dada situação, a significação do ato de linguagem, tanto no que diz respeito à instância de produção quanto no que se refere à instância de interpretação é construído, então, 
nesses três níveis. O situacional considera as circunstâncias dadas pela situação de comunicação, como a legitimidade social exercida pelos sujeitos que Ihes confere (ou não) o direito à palavra, o propósito comunicativo (tema), as intenções desses sujeitos, se estão presentes ou ausentes no momento da troca, que canal (suporte) utilizam, qual o gênero selecionado, etc.

O discursivo define as estratégias utilizadas pelos sujeitos com base nas características que constroem o nível situacional. Assim, estabelece o modo de tomada da palavra, com a seleção do modo de enunciação que explicita o projeto de influência do "eu" sobre o "tu", com base no uso dos modos elocutivo (eu), alocutivo (tu) ou delocutivo (ele). Vejamos cada um deles a seguir:

ELOCUTIVO: revela o ponto de vista do locutor

ALOCUTIVO: estabelece uma relação de influência entre locutor e interlocutor

DELOCUTIVO: apagamento do sujeito falante

Ademais, o nível discursivo estabelece a seleção do modo de organização do discurso, sendo responsável por revelar a intenção do sujeito falante, o qual pode ter por intenção narrar, descrever ou argumentar; e a seleção de textos e discursos, responsável por dialogar com o tema tratado.

O nível semiolinguístico, por fim, refere-se à superfície linguística, selecionada a partir das características que constroem os níveis anteriores.

Dessa maneira, os sujeitos precisam ter competências nos três níveis para interagir um com o outro, sendo capazes de dominar as regras de codificação/decodificação e de organização sintática dos enunciados; evocar textos e discursos alheios importantes para o ato em questão, compreender a organização e função dos mais variados gêneros 
discursivos, posicionar-se de maneira coerente com o ato de linguagem e de acordo com os objetivos visados; considerar todas as circunstâncias materiais da situação de comunicação, cujas características interferem no contrato de comunicação e, logo, na significação do discurso produzido.

A interação estabelecida por meio da leitura, por sua vez, requer ainda mais atenção à construção desses três níveis, uma vez que, a impossibilidade de réplica por parte do leitor impede que falhas na comunicação sejam resolvidas.

Por ser caracterizada por um contrato de não-troca, no qual os conhecimentos prévios do leitor são estabelecidos "a priori" (EMEDIATO, 2007, p. 85) por meio da idealização que o autor faz de seu leitor, cabendo a este procurar meios para preencher os implícitos dados pelo texto, o estabelecimento da significação, por meio da leitura, exige a interação de leitores competentes, que se proponham a penetrar no sentido do texto por meio de uma percepção mais aprofundada. Dessa forma, a leitura competente vai além da "camada superficial" do texto, já que não basta decodificar os significantes, mas é preciso alcançar os múltiplos significados permitidos pelo texto.

Para entender os sentidos de um texto, o leitor precisa ultrapassar o sentido de língua e chegar ao sentido de discurso. Ele deve, portanto, transpor o visível e passar a "enxergar" o invisível, por meio da consideração a todos os níveis que constroem o discurso dado pelo texto. Contudo, essa é uma tarefa difícil, que, em muitos casos, necessita de um trabalho de mediação, devido à maturidade do leitor. É nesse sentido que o ensino e aquisição das competências postuladas por Charaudeau são imprescindíveis para o alcance da interpretação dos sentidos textuais. 
A fim de melhor evidenciar o quanto os significados textuais não são construídos somente no nível superficial da língua, mas, sobretudo, por meio de dados extralinguísticos que preenchem informações do texto e demonstram que o mesmo é construído pela língua em dada situação de interação, o próximo tópico procederá à análise da poesia cidadã de Sérgio Vaz, na qual conhecimentos prévios partilhados entre o poeta e seus leitores são imprescindíveis para a (re)construção dos significados no momento da leitura.

\section{A produção dos sentidos extraídos da leitura da poesia de Sérgio Vaz}

A significação, entendida pela Semiolinguística como um fenômeno preenchido pela linguagem em situações de interação, advém, pois, da união entre dados explícitos e dados implícitos do texto. Os primeiros, ligados à superfície linguística do texto, podem ser facilmente compreendidos pelos leitores, uma vez que seus sentidos partem da decodificação e do uso denotativo da língua. Os implícitos, por sua vez, para serem interpretados, necessitam de habilidades leitoras que permitam que os sentidos textuais sejam preenchidos pelos conhecimentos prévios dos leitores que devem considerar a língua em seu contexto de uso.

Dessa maneira, para o alcance da interpretação textual é necessário que competências nos diversos níveis de construção do texto sejam ativadas por parte dos leitores.

A fim de explicitar a importância das competências de linguagem para a produção e interpretação de textos, nesta seção analisar-se-á a construção do poema "Os 
Miseráveis", de Sérgio Vaz, considerando os três níveis de construção da linguagem, propostos por Charaudeau (2001). Assim como textos de natureza diversa, o poema é construído em três níveis (situacional, discursivo e semiolinguístico), sendo sua significação alcançada por meio da interação entre os interlocutores que ativam seus conhecimentos extralinguísticos para significar a língua. Tal fator demonstra a necessidade de leitores competentes para a concretização da comunicação via texto.

A poesia de Vaz, conforme já foi mencionado em tópico introdutório, nasce em meio à periferia de São Paulo. A voz do poeta é o meio pelo qual ele concretiza a sua visão acerca do mundo, retratando as suas experiências e vivências enquanto homem negro e periférico. No poema analisado, o eu-lírico apresenta sua visão da realidade que o cerca a partir da descrição subjetiva da vida e das oportunidades dos personagens Vitor e Hugo. Tal descrição, ao mesmo tempo em que evidencia uma relação de oposição entre dois personagens, por pertencerem a classes sociais distintas, acaba por igualá-los através do enfoque dado ao caráter e atitudes de cada um deles. Assim, o eu-lírico explicita que essa oposição é inexistente quanto aos atos que praticam, porém revela o quanto a posição social e as ideias preconcebidas sobre classes distintas influenciam a construção da imagem dos indivíduos.

$\begin{array}{ll}\text { Os Miseráveis (Sérgio Vaz) } & \\ \text { Vítor nasceu } & \text { sem mãe, } \\ \text { no Jardim das Margaridas } & \text { sem norte, } \\ \text { Erva daninha, } & \text { sem seta. } \\ \text { nunca teve primavera. } & \text { Pés no chão, } \\ \text { Cresceu sem pai, } & \text { nunca teve bicicleta. }\end{array}$


Hugo não nasceu, estreou.

Pele branquinha,

Nunca teve inverno.

Tinha pai,

tinha mãe,

caderno

e fada madrinha.

Vítor virou ladrão,

Hugo salafrário.

Um roubava pro pão,

o outro, pra reforçar o salário.

Um usava capuz,

o outro, gravata.

Um roubava na luz,

o outro, em noite de serenata.
Um vivia de cativeiro,

o outro, de negócio.

Um não tinha amigo: parceiro.

o outro tinha sócio.

Retrato falado,

Vítor tinha a cara na notícia,

enquanto Hugo

fazia pose pra revista.

O da pólvora

apodrece penitente,

O da caneta

enriquece impunimente.

A um, só resta virar crente, o outro, é candidato a presidente.

(VAZ, 2013, p. 57).

No nível semiolinguístico, as categorias linguísticas nomeiam, qualificam, descrevem ações e estabelecem causas, proporcionando uma relação de oposição entre os personagens, uma vez que o que é definido para um é negado para o outro. Observemos o quadro abaixo:

Quadro 1 - Comparação: Vitor X Hugo

\begin{tabular}{|l|l|}
\hline Vitor & Hugo \\
\hline Nasceu & Estreou \\
Erva daninha & Pele branquinha \\
nunca teve primavera. & Nunca teve inverno. \\
Cresceu sem pai, & Tinha pai, \\
sem mãe, & tinha mãe, \\
sem norte, & caderno \\
sem seta. & caderno. \\
\hline
\end{tabular}




\begin{tabular}{|l|l|}
\hline Pés no chão, & fada madrinha. \\
nunca teve bicicleta. & fada madrinha. \\
Ladrão & Salafrário \\
\hline
\end{tabular}

No entanto, o sentido de negação e oposição inscrito no texto advém do uso conotado de algumas palavras que estabelecem a oposição por meio de convenções estabelecidas entre os usuários da língua. No quadro exposto, é possível perceber que tais oposições não se dão apenas no nível da explicitude, conforme ocorre com o pare "sem pai" X "tinha pai" em que a preposição estabelece um sentido de negação em relação ao verbo "ter". Tais oposições são, predominantemente, construídas no nível da implicitude, como ocorre com o par "nunca teve primavera" $X$ "nunca teve inverno", em que as categorias de língua (advérbio, verbo, substantivo) expressam o mesmo sentido: "ambos não tinham algo"; todavia, as noções simbólicas sobre o que é primavera e o que é inverno, estabelecem o sentido de que o primeiro nunca teve facilidades, enquanto o segundo nunca teve dificuldades, o que demonstra que, nesse par, a oposição não se estabelece pelo sentido de língua dado, mas pelo sentido de discurso, que utiliza as palavras dentro de um quadro de referência e faz com que as noções de "primavera" e "inverno" não remetam às situações usuais de "estações do ano", "mudanças climáticas", mas sim, transcendam a esses sentidos e remetam ao cotidiano de cada classe representada pelos personagens.

Esse sentido de discurso, por sua vez, advém das considerações realizadas às diversas situações comunicativas que fazem parte do repositório mnemônico dos sujeitos participantes do ato de comunicação. Para alcançar a interpretação evidenciada, é necessário, portanto, que autor e leitor partilhem de conhecimentos comuns sobre as situações evidenciadas. 
O uso de palavras que expressam um sentido conotativo faz parte das estratégias utilizadas pelo enunciador, que espera que seu interlocutor possua os mesmos conhecimentos sobre o uso do código linguístico dado e extrapole o sentido de língua. A estratégia comentada, porém, não é a única, nos pares "sem norte" / "sem seta" X "caderno" e "pés no chão" / "nunca teve bicicleta" X "fada madrinha". O enunciador faz uso de categorias de língua diferentes que remetem a significados distintos para, de certa forma, estabelecer uma relação de semelhança entre o que falta em um e o que há no outro. Assim, "não ter norte, não ter seta e [ter] caderno" equivale, especificamente, à situação de desconhecimento pela falta de estudos que tem como consequência a falta de oportunidades em oposição à situação de o sujeito ter tido a oportunidade de estudar e, por isso, ter um quadro mais amplo de oportunidades.

Esses sentidos comentados somente são semiotizados na união do nível situacional com o nível discursivo. No plano discursivo, a intenção comunicativa do eu-lírico, a partir da seleção do modo de organização descritivo, que, no poema em questão descreve ações a fim traçar semelhanças e oposições entre os personagens, somente é interpretada quando se faz a consideração às situações comentadas que fazem com que os termos de caráter subjetivo e conotado sejam semiotizados no sentido para além da superfície linguística, da decodificação.

Da mesma forma, ainda no nível discursivo de construção do poema, a seleção do modo delocutivo, comportamento cuja palavra do outro é apresentada, aparentemente, revela um discurso relatado, no qual a opinião do enunciador é apagada. No entanto, esse apagamento se dá apenas no nível superficial, uma vez que a escolha de termos como "ladrão" e "salafrário", por exemplo, que possuem definições negativas, que denigrem a imagem do ser ao qual fazem referência, aponta especificamente para um 
enunciador que se posiciona sobre a realidade dos personagens e sobre a maneira como são vistos socialmente. Para o primeiro, o termo que o qualifica - ladrão - destaca o ato de criminalidade praticado, tendo como consequência a cadeia; para o segundo, em contrapartida, o termo qualificador - salafrário - dá ênfase apenas à desonestidade da pessoa, deixando em segundo plano os atos ilícitos que ela comete. E são essas nuances advindas da situação comunicativa que acrescentam sentidos aos discursos, demonstrando que este não tem por intenção apenas descrever, mas, sobretudo, apresentar um posicionamento crítico sobre o assunto tratado.

Outra estratégia utilizada pelo eu-lírico é o anúncio da temática que será tratada ao longo do poema. Já no título, o poema deixa implícito o seu tema ao realizar uma intertextualidade com a obra Les Misérables, de Victor Hugo (1862). Enquanto o título faz uma referência direta à obra de Victor Hugo, o texto de Vaz evidencia as circunstâncias que levaram Vítor e Hugo ao crime, realizando uma intertextualidade com a obra francesa. Fiorin afirma que "a intertextualidade é o processo de incorporação de um texto em outro, seja para reproduzir o sentido incorporado, seja para transformá-lo" (1999, p. 30). Desse modo, a poesia tematiza a diferença de classe e as injustiças sociais, reproduzindo o sentido do texto fonte. Além disso, a escolha dos nomes dos personagens é uma alusão ao escritor francês.

Tal estratégia, de acordo com a teoria Semiolinguística, se dá no nível discursivo, por meio dos semas dos textos que são unidos, proporcionando, assim, a intertextualidade por meio da retomada do discurso da obra inspiradora. Essa estratégia semântica, no entanto, precisa de competências voltadas aos textos e discursos que circulam na sociedade dos interlocutores, pois, o desconhecimento do intertexto anula a 
possibilidade de alusão à obra, além de impedir que pressuposições sobre o texto possam ser feitas já no momento da leitura do título.

As construções dadas no nível discursivo e comentadas aqui, por sua vez, apenas são possíveis porque, em meio à interação entre texto e leitor, este recorre aos seus conhecimentos de mundo para significar aquele, interpretando todos os termos apresentados dentro de um quadro de referência construído pelas informações implícitas dadas pela situação comunicativa, como, por exemplo, o lugar de produção do autor - as periferias -, a realidade vivida por essa sociedade, os casos de discriminação social enfrentados por pessoas que pertencem a este meio, as faltas de oportunidades, etc.

Sem a remissão a todos esses aspectos situacionais, que promovem escolhas discursivas, seria, portanto, impossível ao leitor interpretar a totalidade dos sentidos do texto, com a consequência de permanecer apenas no nível superficial da linguagem.

\section{Considerações finais}

A análise realizada permite a observação de que a poesia retrata a diferença de classes e as consequências disso em um país como o Brasil. Através de sua poesia-cidadã, Vaz realiza uma denúncia sobre privilégios e justiça. O poema "Os Miseráveis", por meio de enunciados que se opõem, desvenda uma das maiores mazelas brasileiras: a impunidade. Assim, os personagens apresentam finais distintos, apesar de ambos terem praticados atos ilícitos: Vítor "apodrece penitente", enquanto Hugo "enriquece livremente". Isso revela, portanto, os privilégios de classe, algo tão presente em uma sociedade classista como a brasileira. 
Para que esses significados oferecidos pelo texto sejam alcançados pelo leitor, é necessária uma leitura competente. Desse modo, corroboramos a necessidade de que o texto seja assimilado em sua completude, perpassando o sentido de língua (compreensão) e alcançando o sentido de discurso (interpretação).

Portanto, entendemos que a língua deva ser trabalhada em sala de aula como uma prática social dotada de significados. É imprescindível a interseção entre o estudo de língua portuguesa e o estudo de literatura. Por meio da leitura proficiente de textos literários, o aluno, além de adquirir a língua, será introduzido em temas políticos, sociais, econômicos, emocionais, contribuindo para o reconhecimento de seu papel enquanto sujeito histórico.

Acreditamos, portanto, que os textos literários, enquanto objetos de estudo, trazem a possibilidade de o docente realizar um trabalho no qual as três competências de leitura evocadas por Charaudeau sejam desenvolvidas, favorecendo à reflexão e à construção de uma criticidade, formando, de fato, leitores competentes.

\section{Referências}

CHARAUDEAU, Patrick. Linguagem e discurso: modos de organização. 2 ed. São Paulo: Contexto, 2016. . Discurso das mídias. Tradução de Angela S. M. Corrêa. São Paulo: Contexto, 2007. . Uma análise semiolinguística do texto e do discurso. In: PAULIUKONIS, M. A. L.;

GAVAZZI, S. (Orgs.). Da língua ao discurso: reflexões para o ensino. Rio de Janeiro: Lucerna, 2005, p. 11-27.

De la competencia social de comunicacion a las competencias discursivas. Revista Latino-Americana de Estudios del Discurso, Caracas, Venezuela, v. 1, p. 1-9, 2001. 
Disponível em: <http://www.patrick-charaudeau.com/De-la-competencia-social-de.html >. Acesso em: 4 nov. 2017.

EMEDIATO, Wander. Contrato de leitura, parâmetros e figuras de leitor. In. MARI, Hugo; WALTY, Ivete; FONSECA, Maria Nazareth Soares. Ensaios sobre leitura. 2 ed. Belo Horizonte: Editora PUC Minas, 2007, p. 83-98.

FIORIN, José Luiz. Polifonia textual e discursiva. In.: BARROS, Diana Pessoa; FIORIN, José Luiz (Orgs.). Dialogismo, polifonia e intertextualidade: em torno de Bakhtin. São Paulo: Edusp, 1999.

REBELLO, Ilana da Silva. Ensinar a ler para além do visível: do sentido de língua ao sentido de discurso. Cadernos de Letras da UFF, Niterói, Rio de Janeiro, v. 26, n. 52, p. 331-348, 2016.

VAZ, Sérgio. Colecionador de pedras. São Paulo: Global, 2013.

\footnotetext{
'Quebrada(s): Local com pouca segurança e que pode envolver riscos quando visitado. Periferia.

"i "A construção do sentido, através de qualquer ato da linguagem, ocorre por meio de um sujeito que se direciona a outro sujeito, dentro de uma situação específica de troca, o que parcialmente sobredetermina a escolha dos recursos de linguagem que podem ser utilizados. Isto levou-me a desenvolver um modelo que consiste em três níveis, com três tipos correspondentes de competência para o assunto: nível situacional e competência situacional, nível discursivo e competência discursiva, nível "semiolinguístico" e competência 'semiolinguística'” (tradução nossa).
}

Recebido em 15 de março de 2018.

Aceito em 17 de maio de 2018. 